\title{
Bitki Paraziti Nematodlarla Mücadelede Biyoteknolojik Yaklaşımlar*
}

\author{
Zeliha Şahin ${ }^{1}$, Hayriye Didem Sağlam Altınköy ${ }^{2 \dagger}$ \\ ${ }^{1}$ Kirsehir Ahi Evran University, Faculty of Agriculture, Departmant of Agricultural Biotechnology, Kirsehir, Turkey, (ORCID: 0000-0002-9063-4474), \\ zlh.shn91@gmail.com \\ 2* Kirsehir Ahi Evran University, Faculty of Agriculture, Departmant of Plant Protection, Kirsehir, Turkey, (ORCID: 0000-0001-8925-1305), \\ didemsaglam@ahievran.edu.tr
}

(İlk GelişTarihi 19 Mayıs 2021 ve Kabul Tarihi 18 Aralık 2021)

(DOI:10.31590/ejosat.939277)

ATIF/REFERENCE: Sahin, Z. \& Saglam Altınkoy, H.D. (2021). Biotechnological Approaches to Control of Plant Parasitic Nematodes. European Journal of Science and Technology, (31), 706-712.

$\ddot{O} \mathbf{z}$

Dünya nüfusunun her geçen gün artması, tarımsal üretimden istenen yüksek verim beklentisini de artırmaktadır. Bu beklentinin karşılanması esnasında biyotik ve abiyotik faktörlere bağlı sorunlar ortaya çıkmaktadır. Biyotik faktörler içerisinde bulunan bitki paraziti nematodlar yıllık ortalama 125 milyon dolarlık ürün kaybı ile önemli bir yere sahiptir. Bitki paraziti nematodlarla mücadelede yaklaşık 8 milyon dolarlık pazara sahip kimyasal mücadele ilk sırada yer almaktadır. Kimyasal ilaçların çevreye, insanlara ve hedef alınmayan organizmalara olan olumsuz etkileri dolayısıyla yeni alternatif mücadele yöntemleri geliştirilmelidir. Son yıllarda biyoteknolojik yöntemler kullanılarak bitki paraziti nematodların kontrolü çalışmaları hızla artış göstermektedir. Bu metotlar nematodlara karşı doğal dayanıklıklar, bitki RNA'sının susturulması, proteinaz inhibitörlerinin kullanımı, lektinler aracılığı ile sağlanan dayanıklık ve Bacillus thuringiensis (Bt) Cry proteinleri aracılığı ile sağlanan dayanıklıklar şeklinde sıralanabilir. Bitki paraziti nematodları kontrol etmek için kullanılan bu yeni biyoteknolojik yöntemler kısa sürede yüksek verim ve kaliteli ürünler üretmek için kullanılabilmektedir. Bu çalışmada bitki paraziti nematodlarla mücadelede biyoteknolojik yaklaşımlar derlenmiştir.

Anahtar Kelimeler: Bitki Paraziti Nematodlar, MücadeleYöntemleri, Biyoteknoloji

\section{Biotechnological Approachesto Control of PlantParasitic Nematodes}

\begin{abstract}
The World population is increasing rapidly therefore, it is increasing the expectation of high efficiency demanded from this agricultural production. During the supply of expectations problem arise belonging to biotic and abiotic factors. Plant parasitic nematodes, one of the biotic factors, cause yield losses around 125 million dollars annually. Control of plant parasitic nematodes is mostly done by chemical pesticides and have place in market approximately 8 million dollars. Chemical pesticides affect human, environment and non-target organisms negatively therefore new alternative control methods need to improve. Biotechnological control methods for plant parasitic nematodes have increased rapidly in recent years. These methods are natural resistance, RNA interference, proteinase inhibitor, lectin base control and Bacillus thuringiensis (Bt) based control. This new approaches of biotechnological methods for controlling plant parasitic nematodes can use for producing high yield and quality products in short period. In this study, biological approaches to control of plant parasitic nematodes have been reviewed.
\end{abstract}

Keywords: Plant Parasitic Nematodes, Control Methods, Biotechnology

\footnotetext{
* Bu çalışma Zeliha ŞAHİN'in Yüksek Lisans seminerinden üretilmiştir. Makale 16-18 Kasım 2017 tarihlerinde Osmaniye'de düzenlenen "1. Uluslararası İleri Araştırmalar ve Mühendislik Kongresi’nde" poster olarak sunulmuş ve kongre kitabında özeti basılmıştır.

$\dagger$ Corresponding Author:didemsaglam@ahievran.edu.tr
} 


\section{Giriş}

Tarımsal üretim insan beslenmesinde önemli bir kaynaktır. Sağlıklı bir insan günlük olarak kullandığ 1 enerjinin \%37-43'ünü tarımsal besinlerden karşılamaktadır (Pekcan ve ark., 2006). Bu ihtiyacı karşılamak amacıyla tarımsal üretim her geçen yıl hızlı bir ivme ile artmış, bu artışta verim ve kalite önemli bir kriter haline gelmiştir. Bu hızlı ve seri üretim esnasında birçok biyotik ve abiyotik faktörlere bağlı üretim sorunları ile karşılaşılmaktadır. Bunlar içerisinde bitki paraziti nematodlar dünya genelinde \%12.6 oranında ürün kayıplarına sebep olması ile önemli bir yere sahiptir (Lopes-Caitarve ark., 2019). Nematodlar, her türlü iklime uyum sağlamış; bitkiler, insanlar ve hayvanlarda parazit olarak bulunan, toprak ortamında serbest yaşayan saprofit formları ile geniş yayılış alanına sahip bir canlı grubudur (Freckman ve Baldwin,1990; Boag ve Yeates, 1998). Bitki paraziti nematodlardan şu ana kadar 4305 türü tespit edilmiş olup bunların tarımsal üretime verdiği zararın yaklaşık 80 milyon dolar olduğu tahmin edilmektedir (Nicol ve ark., 2011; Maggenti, 1991). Nematodlar renksiz, saydam görünüşlü ve gözle görülmesi oldukça zor olan mikroskobik canlılardır. Bitki paraziti nematodların ergin öncesi dönemlerine "larva" denir ve yaşamları boyunca 4 gömlek degiştirerek ergin hale geçerler. Yaşamlarını sürdürmek için uygun konukçunun bulunmadığı durum da bazı türler ölürken bazı türlerin ise yumurtaları dormansi durumda toprakta yıllarca canlılığını koruyabilir (Agrios, 2005). Gerekli konukçuyu bulup ergin hale geçen bireyler uygun ortam ve koşullar sağlanırsa bütün yıl devamlı çoğalabilirler. Geniş bir yayılış alanına sahip olan nematodlar son yıllara kadar en az bilinen organizma grupları arasında yer almışlardır. İlk çalışmalar 19. yüzyılda kültür bitkilerinde oluşturdukları zararlarla fark edilmiştir (Thorne, 1961). Nematodlar bitki üzerinde kök, gövde, yumru ve yapraklardan beslenerek zarar oluşturmaktadır. $\mathrm{Bu}$ beslenme esnasında salgıladıkları toksik salgılar bitkilerde urlanmalar, yaralar, solma, sararma, bodurlaşma, renk değişiklikleri, kıvrılma, yumru ve köklerde saçaklanma, yumuşama ve çürümeler meydana getirir (Kepenekci, 2012). Ayrıca nematodların beslenmek için açtıkları yaralardan bakteri ve funguslar rahatlıkla giriş yapabilmekte böylelikle bitki üzerinde direk zararlarının yanı sıra indirek zararlara da sebep olmaktadırlar (Perry ve Moens, 2006; Kepenekci, 2012). Bu zararların yanı sıra bir diğer zararları ise bitki virüslerinin taşınmasında oynadıkları roldür (Harris, 1981). Hohn (2007), fungus, böcek ve nematod gibi vektörlerle bitki virüslerini ortalama \%80'sinin taşındığını belirtmiştir.

Tarım alanlarında bu denli ürün kayıplarına neden olan bitki paraziti nematodların zararını en aza indirmek amacı ile değişik mücadele yöntemleri kullanılmaktadır. Bu yöntemlerden en yaygın olanı kimyasal mücadeledir ve yıllık 1.3 milyar dolarlık bir paya sahiptir (Oka, 2020). Ancak her ne kadar kimyasal mücadelenin özellikle uygulama kolaylığı ve ucuz olması üreticileri cezbetse de bitki paraziti nematodlar üzerinde kesin ve uzun vadeli sonuçlar ortaya koyamamaktadır. Bir diğer mücadele yöntemi ise biyolojik mücadeledir. Bitki paraziti nematodların biyolojik mücadelesinde kullanılan veya kullanılma potansiyeli olan çok sayıda doğal düşman vardır. Predatör funguslar (Arthrobotrys dactyloides), endoparazit funguslar (Purpureocillium lilacinum (Syn. Paecilomyces lilacinus), Pochonia chlamydosporia, Beauveria bassiana), bakteriler (Pasteuria penetrans) ile collembola, tardigrade, akarlar ve entomopatojen nematodlar gibi predatörleri bulunmaktadır (Kepenekci, 2012). Bu yöntem son yıllarda devlet teşviki ile de yaygınlaştırılmaya çalışılsa da yüksek maliyetli olması ve bazı durumlarda doğal düşmanların sı sık salım yapılması gerekliliği gerçeği bu yöntemi dezavantajlı hale getirmektedir. Kültürel önlemlerle yapılan mücadelede ise toprak işlemenin yapılması ile bitki kök sisteminin daha kuvvetlenmesi sağlanır. Tohum temizliğine dikkat edilerek bitki paraziti nematodlarla bulaşık olmayan tohum ve yumruların ekim dikimlerinin sağlanması, sulama suyunun salma sulama şeklinde değil damlama sulama sistemlerinin kurularak verilmesi ile bitki paraziti nematodların bir yerden başka bir yere geçişinin engellenmesi sağlanabilmektedir. Bunun yanında dayanıklı çeşit kullanımı ile de bitki paraziti nematodların mücadelesi yapilabilmektedir.

Bitkilerin, hastalık ve zararlılara karşı dayanıklılık geni taşıdıkları bu yüzyılın başından beri bilinmektedir. Bu genlerin kullanımı ile çiftçilerin yoğun kimyasal ilaç tüketimleri sınırlanmıştır (Keen, 1999). Son yıllarda üzerinde yoğun olarak çalışılan ve önemli gelişmeler kaydedilen biyoteknolojik çalışmalar bitki paraziti nematodlarla mücadele de yeni bir ufuk açmış ve olumlu sonuçlar ortaya koymuştur. Ancak biyoteknolojik çalışmalar konusundaki bilgilerin yanlış ve eksik bilinmesine bağlı olarak insanlar ön yargılı yaklaşmaktadırlar. Biyoteknolojik çalışmalar ile zamanın önemli olduğu gelecek kuşaklar için kısa zamanda kaliteli ve yüksek verimli ürün elde etme olanağı sağlanmaktadır. Bitki paraziti nematodlarla ilgili ilk biyoteknolojik çalışmalar kök ur nematodları üzerinde başlamış daha sonra kök lezyon nematodları ve diğer nematod türleri ile devam etmektedir.

\section{Bitki Paraziti Nematodlarla Mücadelede Biyoteknolojik Yaklaşımlar}

Tarımsal üretimde hedeflenen yüksek verim ve kaliteli ürün, hastalık ve zararlılardan ari üretim son yıllarda tarımsal biyoteknoloji alanının gelişmesini sağlamıştır. Bitki biyoteknolojisi ile ilgili ilk çalışmalar 1980'li yıllarda Agrobacterium'un neden olduğu kök boğazı hastalığının moleküler mekanizmasının bulunması ile başlamıştır. Daha sonra bitki biyoteknolojisinin temeltaşı olan Agrobacterium bakterisinin bitkilere istenilen özellikleri aktarımında kullanılması ile bitki biyoteknolojisi alanındaki çalışmalar hız kazanmıştır (Özcan, 2001). Bu gelişmelerden sonra tarımsal özellikleri kodlayan genlerin değişik teknikler kullanılarak çok sayıda bitki türüne aktarımı yapılmıştır. Entomoloji alanındaki ilk çalışmalar böceklerde dayanıklılık üzerine yapılırken son yıllardaki çalışmalar bitki paraziti nematodlar üzerinde yoğunlaşmıştır.

Bitki paraziti nematodlarla mücadelede biyoteknolojik çalışmalar 4 başlık altında incelenebilmektedir:

2.1.Bitki RNA’sının Susuturulması ile Bitki Paraziti Nematodların Baskılanması

2.2.Transgenik Proteinaz İnhibitör (PI) Tabanlı Bitki Paraziti Nematodların Kontrolü

\subsection{Lektinler Aracılığı ile Sağlanan Nematod Direnci}

2.4.Bacillus thuringiensis (Bt)'nin Cry Proteinleri Aracılığı ile Sağlanan Nematod Direnci 


\subsection{Bitki RNA'sının Susturulması ile Bitki Paraziti Nematodların Baskılaması}

RNA interferans, "gen susturulmast" olarak bilinen bu yöntem spesifik genlerin işlevini engellemede kullanılan bir tekniktir (Dağeri ve ark., 2012). Geliştirilen bu metod sayesinde son yıllarda bitki koruma alanında önemli gelişmeler sağlanmıştır.

Bitki paraziti nematodlarda gen susturmak için RNA etkileşimi (RNAi) uygulamaları yapılmış ve bir nematodun genini hedefleyen çift sarmallı RNA (dsRNA)'yı bulunduran bitkilerde direncin sağlandığı saptanmıştır (Gheysen ve Vanholme, 2007; Lilley ve ark., 2007). dsRNA tarafindan kontrol edilen gen susturucu ilk olarak Caenorhabditis elegans (Maupas) üzerinde Fire ve ark. (1998) tarafindan yapılmıştır. Bu çalışmanın etkisi 2006 yılında Nobel Fizyoloji ve Tıp Ödülü’nü Andrew Fire ve CraigMello'a kazandırarak kabul edilmiştir. Benzer bir çalışma bitkiler için transkripsiyon sonrası gen susturulması olarak tarif edilmiştir (Jorgensen ve ark., 1996; Waterhouse ve ark., 1998). Bitki paraziti nematod genlerinin fonksiyonel analizi ilk olarak 2002 yılında yapılmış, daha sonra Lilley ve ark., (2007) ve Fleming ve ark., (2007) tarafindan yapılan çalışmalar ile çeşitli doku ve hücrelerde bir dizi gen topluluğunun hem kist hem de kök-ur nematodlarına karşı bitkide gen susturma işlemleri ile başarı sağlanmıştır. Yadav ve ark., 2006 yılında Meloidogyne türleri üzerinde yaptıkları çalışmada tütün bitkisinde bu nematod türünün gelişimini engelleyici kromotıtlerin RNA sarmalına eklenmesi ile $M$. incognita 'ya karşı \%90'dan fazla direnç sağlamışlardır. Başka bir çalışmada ise in vitro koşullarında 16D10 geninin dsRNA'da M. incognita 2. dönem larvalarına verilmesi ile Arabidopsis (Pilosella siliquosa) köklerinde bulunan nematod yoğunluluğunun \%82 oranında baskılandığı ortaya konulmuştur. Arabidopsis 'in Meloidogyne türleri ile enfekte edilmesi ile larva sayısında azalma ve toplam üremede \%63-90 oranında bir düşüş gözlenmiştir. Bu çalışma ile $M$. incognita, $M$. hapla, $M$. arenaria ve $M$. javanica'ya karşı geniş açıda dayanıklılık gösterdiği belirlenmiştir (Huang ve ark., 2006b) (Tablo 1). Bu çalışmalar 1şığında Fairbairn ve ark., (2007) MjTis11'in tütün üzerinde DNA ve RNA' daki bir bölge olan “hairpin" yapılarındaki bölgenin susturulması sonucu $M$. javanica'nın hem direncini hem üremesini etkilediğini ortaya koymuşlardır. Steeves ve ark., 2006 yılında yapmış oldukları çalışmada transgenik soya fasulyelerinde zarar yapan $H$. glycines in MSP (Majör Sperm Proteini) geni hairpin yapısı bitkiye aktarılarak kök dokularında nematod üremesini $\% 75$ oranında azalttığ varmışlardır. Valentine ve ark., 2007 biraz farklı bir yaklaşım ile Arabidopsis üzerinde RNA'yı susturmak için $H$. schachtii'de glyceraldehyde-3-phosphatedehydrogenase (GAPDH) geni kullanmışlar ve 14 gün sonra dişi nematodların yoğunluğunda \%10-15 azalma olduğunu belirtmişlerdir. Bu yaklaşım dayanıklı bitki üretimi için yeterli olmamasına rağmen potansiyel hedef genlerin hızlı test edilmesinde önemli bir gelişme olduğu belirtilmiştir (Fuller ve ark., 2008). Huang ve ark., (2006a) transgenik bitkilerde hem tam uzunlukta 16D10 dsRNA hem de işlenmiş siRNAs'ların varlığını belirtirlerken, Steeves ve ark., (2006), H. glycines MSP sekansına karşılık gelen siRNAs'ları tespit etmişler fakat dsRNA'yı tespit etmekte başarısız olmuşlardır. Kist nematodlarının genlerini susturmak için yapılan birçok çalışmaya rağmen (Steeves ve ark., 2006; Valentine ve ark., 2007) başarı oranı düşük bulunmuştur (Gheysen ve Vanholme, 2007). Bu durumun nedenini Fuller ve ark., (2008) nematod türleri arasında bile değişen beslenme şekli ve beslenme bölgesinin bitki hücresinden alabileceği molekülün maksimum boyutundaki farklılıkların oluşması olduğunu belirtmişlerdir. Şu anda nematod genlerinin susturulması görevini dsRNA mı yoksa siRNAs'mı üstleniyor bu konu ile ilgili hala net bir sonuç bulunmamaktadır (Fuller ve ark.,2008).

\subsection{Transgenik Proteinaz İnhibitör (PI) Tabanlı Bitki Paraziti Nematodların Kontrolü}

Proteinaz inhibitörleri (PI), birçok bitkide doğal olarak bulunan ve protein yapısı ile bitkinin doğal savunmasında yer alan moleküllerdir (Ryan, 1990). Proteinaz inhibitörlerini içeren yaklaşık 20 kadar protein familyası bulunmakta ve bu değişik familyalara ait proteinler 40 ile 180 arası amino asit içeren polipeptidlerden oluşup oldukça kararlı yapılara sahiptirler (Baker ve ark., 1997). Proteinaz inhibitörlerinin böceklere dayanıklı transgenik bitki geliştirilmesinde kullanımına yönelik ilk çalışma 1987 yılında yapılmıştır (Hilder ve ark., 1987). Bu çalışmada börülceden izole edilen PI'nin tütüne aktarılması ile elde edilen transgenik bitkilerin Heliothis virescens (Fabricius) (Lepidoptera: Noctuidae)'e karşı dayanıklılık gösterdiği saptanmıştır. PI taşıyan transgenik bitkilerin gelişiminde önemli yere sahip diğer bir çalışma ise patates ve domates proteinaz inhibitörü-II'nin tütüne aktarımı ile geliştirilen bu transgenik bitkilerin H.virescens larvalarının gelişimini engellemesi ve büyümesini baskılamasıdır (Vishnudasan ve ark., 2005). Böceklere dayanıklılıkta aktif olarak kullanılan bu inhibitör türünün 1990'lı yılların başında nematodlara dayanıklılık çalışmalarında da kullanılabileceğine dair görüşler ortaya çıkmaya başlamıştır (Urwin ve ark., 1997; Vai ve ark., 1998). PI' lerin nematodlara dayanıklılık potansiyeli ilk olarak "serine börülce trypsin inhibitörü (CpTI)" kullanılarak araştırılmıştır. Hepher ve Atkinson (1992) yaptıkları çalışma ile CpTI'nin G.pallida'nın cinsel yapısını bozup daha az baskın erkek bireylerin oluşumunu sağladiğı ve ortamda nematod popülasyonunun azalması ile zararın daha az seviyede olduğu ortaya konulmuştur. Diğer bir çalışma ise CpTI'nın $M$. incognita'nın üremesini azalttıg1 ancak G. pallida'nın üremesi üzerine bir etkisi olmadığını belirtmiştir (Hepher ve Atkinson, 1992; Urwin ve ark., 1998). Cai ve ark. (2003) PI'nın $H$. schachtii'nin büyüme ve gelişmesini engellediğini tespit etmişlerdir. $H$. avenae ile ilgili yapılan bir çalışma ise transgenik buğdaydan elde edilen PI'nın tahıl kist nematodunun gelişimini ve büyümesini baskıladığını belirtmiştir (Vishnudasan ve ark., 2005).

Ekonomik açıdan ciddi zararlara sebep olan H. schachtii ve M. incognita'ya karşı kullanılan cystatin (Oc-I) inhibitörü dişi bireyler üzerinde yumurta, üretme ve gelişme aktivitelerini kısıtladığı belirlenmiştir (Urwin ve ark., 1997). Dişi nematodların sayısında $\% 35$ azalma ve üremede $\% 69$ bir gerileme tespit edilmişken, $\% 81$ oranında nematodların baskılanabildiği belirtilmiştir (Urwin ve ark., 2000). OcI $\Delta$ D86 cystatin ile ise $M$. incognita 'nın üremesi \%55 oranında azaldığ 1 bulunmuştur (Vai ve ark., 1998). Cystatin-expressing ile üretilen patates bitkilerinin doğal parazitoidlere (Cowgill ve ark., 2002a, 2004), toprak faunasina (Cowgill ve Atkinson, 2003), hedef alınmayan böcek veya doğadaki serbest canlılara (Cowgill ve ark., 2002b) zarar vermediği farklı araştırıcılar tarafından belirtilmiştir. Bu çalışmalar ile PI'nın bitki paraziti nematodları baskılamada etkili olduğu ortaya konulmuştur. 
EuropeanJournal of ScienceandTechnology

Tablo 1. Bitki paraziti nematodlara dayanıklllıkta susturulan bitki genleri (Fosu-Nyarko ve Jones, 2015)

\begin{tabular}{|c|c|c|c|c|}
\hline Nematod & Susturulmuş Gen & Bitki & Etkinlik Seviyesi & Kaynak \\
\hline \multirow{4}{*}{ M. incognita } & SNF kromatin yeniden modellenmesi & Tütün & $\% 90$ 'dan fazla nematod azalmış & \multirow{2}{*}{ Yadav ve ark., (2006) } \\
\hline & Pre-mRNA birleştirme faktörü (prp-21) & Tütün & \%90'dan fazla nematod azalmış & \\
\hline & Mitochondrialstress- 70 protein & Soya fasulyesi & \%92 gal oluşumu engellenmiş & \multirow[b]{2}{*}{ İbrahim ve ark., (2011) } \\
\hline & Tyrosinephosphatase & Soya fasulyesi & $\% 95$ gal oluşumu engellenmiş & \\
\hline \multirow[b]{2}{*}{ M. javanica } & Nematodefektör protein (NULG1a) & Arabidopsis & \%88'den fazla nematod azaltılmış & Lin ve ark., (2013) \\
\hline & Salgilanan Peptit (16D10) & Arabidopsis & $\begin{array}{l}\text { \%90-93 yumurta oluşumunun azaldığı, } \\
\text { \%63'ten fazla gal oluşumunun azaldığı }\end{array}$ & Huang ve ark., (2006a) \\
\hline M. halpa & Salg1lanan Peptit (16D10) & Arabidopsis & \%69-73 yumurta oluşumunun azaldığı & Huang ve ark., (2006b) \\
\hline \multirow{2}{*}{ M.chitwoodi } & Salg1lanan Peptit (16D10) & Arabidopsis & $\begin{array}{l}\text { \%57 yumurta paketinin azaldığı, } \% 67 \\
\text { yumurta oluşumunun azaldığı }\end{array}$ & \multirow{2}{*}{ Dinh ve ark., (2014) } \\
\hline & Salgilanan Peptit (16D10) & Patates & $\begin{array}{l}\text { \%71 yumurta paketinin azaldığ }, \% 63 \\
\text { yumurta oluşumunun azaldığı }\end{array}$ & \\
\hline \multirow{3}{*}{ H. glycines } & Rİbozomal protein 3a (rps-3a) & Soya fasulyesi & \%87 dişi gelişiminin azaldığ & \multirow{3}{*}{ Klink ve ark., (2009) } \\
\hline & Spliceosomal SR protein $(s p k-1)$ & Soya fasulyesi & \%88 dişi gelişimininin azaldığı & \\
\hline & Synaptobrevin $(s n b-1)$ & Soya fasulyesi & \%93 dişi gelişiminin azaldığ 1 & \\
\hline \multirow{3}{*}{ H.schachtii } & SKP1-like protein $(8 \mathrm{H} 07)$ & Arabidopsis & \%50'den fazla dişi gelişiminin azaldığ1 & Sindhu ve ark., (2009) \\
\hline & Nematodun salgıladığ1 peptid (Hs4F01) & Arabidopsis & \%55 dişi gelişiminin azaldığ & Patel ve ark., (2008) \\
\hline & $30 \mathrm{C} 02$ effector protein & Arabidopsis & \%92'den fazla dişi gelişiminin azaldığı & Hamamouch ve ark., (2012) \\
\hline
\end{tabular}

\subsection{Lektinler Aracılığı ile Sağlanan Nematod Direnci}

Lektinler çoğu bitkide bulunan, glikoprotein, glikolipid ve polisakkaridlere bağlanma özelliği gösteren protein gruplarıdır (Öktem, 2001). Bitki lektinleri heterojen ve biyokimyasal açıdan karmaşık protein gruplarını içerir. Lektinlerin ana rolünün patojeni tanıma, stresi algılama ve savunma mekanizmasını oluşturmak olduğuna inanılmaktadır. Pek çok bitki lektinleri bitkide az rastlanan veya bulunmayan kitin gibi glikanları bağladığı için savunma rolünü üstlenmektedir (Peumans ve Van Damme, 1995). Depolama organlarında bitki lektinlerinin birikimi de pasif bir savunma mekanizması rolünü işaret eder. Lektin genleri, bitki paraziti nematodlarda dahil birçok patojene tepki vermek için bitkiyi uyarmaktadır (Oka ve ark., 1997; Jammes ve ark., 2005; Fuller ve ark., 2007). Lektin genleri nematodlar üzerinde bulunan glikoproteinlere bağlananlar dışındakilerle veya bağırsaklarda bulunan glikoproteinlerle etkileşime girerek etki gösterebilirler (Fuller ve ark., 2008). Bu alandaki ilk çalışma Marban-Mendoza ve ark., (1987) tarafından yapılmış ve Concanavalin A uygulanması ile domates bitkisi köklerinde $M$. incognita populasyonunu \%75 oranında düşürdüğünü ortaya koymuşlardır. Lektinler, dışardan gelen sinyallerin ve uyarıların bitki paraziti nematodlar tarafindan algılanmasından sonra bitki köklerindeki uygun genin ekspresyonu ile gen ürünleri hücresel veya kök salınımı için yönlendirilirler böylece önemli ölçüde direnç meydana gelmiş olur.

Bitki paraziti nematodlara karşı Kardelen lektini (Snowdrop Lectin [GNA])'nin dayanıklılık potansiyeli tek başına ve CpTI ile transgenik kolza'da $P$. neglectus ve $H$. schachtii'ye karş1 test edilmiştir. GNA ve CpTI'nin birlikte aktarıldığı çeşitte yaklaşık $\% 25 \mathrm{H}$. schachtii ve \%75 P.neglectus'un baskılandığ belirlenmiştir (Burrows ve De Waele, 1997). Transgenik patates bitkisine aktarılan farklı dozlarda (\%0.1-0.5) GNA'in Patates kist nematodu (G.pallida)'na karşı farklı dayanıklılık mekanizması gösterdiği belirlenmiş. \%0.25 konsantrasyonda GNA eklenen transgenik patates bitkisinde G.pallida popülasyonu $\% 50$ oranında düşerken, $\% 0.5$ konsantrasyonunda GNA eklenen bitkide G.pallida popülasyonun azalması tespit edilmemiştir. $\mathrm{Bu}$ iki deneme sonucuna göre GNA 'nın bitki paraziti nematodlara dayanıklı transgenik bitki üretiminde kullanılma potansiyelinin olduğu ancak dayanıklılığın tam olarak bilinmeyen kritik seviyedeki GNA'a bağlı olduğu belirtilmiştir. En etkili GNA konsantrasyonu farklı nematod türüne karşı farklı duyarlılık gösterebilmektedir. Çok fazla veya çok az GNA önemsiz bir etkiye sahip olabilir, hatta nematod popülasyonunu bile artırabilmektedir (Burrows ve De Waele, 1997). Bu konuda daha fazla çalışmaya ihtiyaç duyulmaktadır. 


\subsection{Bacillus thuringiensis (Bt)'nin Cry Proteinleri Aracılığı ile Sağlanan Nematod Direnci}

Bacillus thuringiensis genellikle toprakta yaşayan gram pozitif bir bakteridir (Öktem, 2001). Uzun yıllardır böceklerde hastalık meydana getirdiği bilinmektedir. Biyolojik mücadele ajanı olarak kullanımında insan ve hayvan sağlı̆̆ına zararsız olması, doğaya toksik olmaması, depolanabilmesi, bitki koruma alet ve ekipmanları ile kolay kullanımı avantajları arasındadır (Thurau ve ark., 2010, Toros ve ark., 1991). B.thuringiensis kristal halinde toksine sahiptir. Bu toksin böcek midesinde etkili olan $\delta$-endotoksine dönüşerek dağılır ve ölüme sebep olur. B.thuringiensis ${ }^{\text {'de }} \delta$-endotoksin proteinin sentezinden sorumlu olan genler Cry genleridir. Cry genleri farklı gruplar altında toplanmaktadir. Cry-IA, Cry-IB, Cry-IC, Cry-IH Cry-2A toksinleri Lepidoptera takımında, Cry-3A ve Cry-6A toksinleri Coleoptera takımında ve Cry-I0A ve Cry-I1A toksinleri ise Diptera takımında etkili olduğu bilinmektedir.

Bunlara ilave olarak Cry-3A Cry-6A, Cry- 5B, Cry-I2A ve Cry-I3A nematodlara karşı etkili olduğu belirtilmiştir (Thurau ve ark., 2010). Bt proteininin böcekler üzerinde yapılmış birçok başarılı çalışmadan çok sonra nematisid etkisi olduğu ortaya çıkmıştır. Bt toksininin ilk nematısid olarak potansiyeli 2000 yılında Marroquin ve ark. (2000) tarafından belirlenmiştir. $C$. elegans üzerinde yapılan bu çalışmada Cry5B ve Cry6A genlerini denemişler ve Cry5B'nin nematodun üremesini azaltıp, ölüm oranını arttırdığını tespit etmişlerdir. Nematisidal etkinin böceklerdekine benzer bir şekilde bağırsağa zarar veren mekanizmadan kaynaklandığı belirlenmiştir (Thurau ve ark., 2010). Böylelikle Bt proteinlerinin bitki paraziti nematodlar arası ilişkinin ölümcül ve toksik etkileri ortaya konulmuştur (Wei ve ark., 2003; Li ve ark., 2007). Cry6A geni, domates köklerindeki M.incognita ile mücadelede kullanılmış ve nematodun yumurta kümelerinde $\% 60$ ve yumurta oluşumunda da \%36 oranında azalmaya sebep olduğu tespit edilmiştir (Li ve ark., 2007, Atkinson ve ark., 2009). Bitki paraziti nematodların beslenme tüpleri moleküler bir süzgeç gibi görev yapmaktadır. Gerekli molekülleri alırken diğerlerini bırakır. Meloidogyne türlerinin, kist nematodlarına göre daha büyük partiküllü molekülleri yutabildiği düşünülmektedir (Li ve ark., 2007). H.schachtii'nin yaklaşı 23 kDa'nun üzerindeki molekülleri yutamadığı Urwin ve ark., (1998) tarafından belirlenmiştir. Molekül büyüklük sınırlaması durumu geniş çaplı bitki paraziti nematodların kontrolünde $\mathrm{Bt}$ geni taşıyan transgenik bitkilerin geliştirilmesinde sınırlamalara neden olmaktadır (Fuller ve ark., 2008).

\section{Sonuç}

Günümüzde dünya nüfusu 7 milyarken, bu rakamın 2050 yılında yaklaşık 10 milyar olacağ paralel bitkisel üretiminde artması gerekmektedir. Ancak her geçen gün tarım alanlarının amaç dışı kullanımı, klasik ıslah yöntemleri kullanılarak verim artışının belli bir noktaya gelmesi ile birim alandan alınacak ürün kısıtlanmaktadır. Ayrıca yoğun kimyasal gübre uygulamaları ve pestisit kullanımı toprak, su ve besin kirliliğine sebep olmakta bu da insan ve çevre sağlığını olumsuz yönde etkilemektedir. Daha sağlıklı ve sürdürülebilir bir tarımsal üretim için alternatif mücadele metotları geliştirilmeye çalışılmaktadır. Tarımsal üretimi arttırmada özellikle hastalık, zararlı ve yabancı otlara karşı biyoteknolojik metotlar üzerine çalışmalar gün geçtikçe artmaktadır. Toprak kökenli bir zararlı olması dolayısıyla bitki paraziti nematodlarla mücadele oldukça zordur. Kimyasal mücadeleye alternatif yöntemlerden dayanıklı çeşit kullanımı, üzerinde en fazla çalışılan konular arasındadır. Dayanıklı çeşit kullanımı ile bitki paraziti nematodların üremesi baskılanıp, ekim nöbeti süresi kısaltılabilmekte dolayısıyla bu zararlılarla mücadelede başarılı ve ekonomik bir yöntem olarak karşımıza çıkmaktadır. Domatese $\mathrm{Mi}$ geni aktarılarak Meloidogyne türlerine karşı, patatese H1 dayanıklılık geni aktarılarak G. rostochiensis 'e karş1 başarılı sonuçlar alınmıştır (Bakker ve ark.,2004). Bunların yanında 11 Cre gen serisi Avustıralya da tanımlanlanmış (özellikle Cre1, Cre3 ve Cre8) ve geri melezleme ile buğday bitkisine aktarımı sağlanmış olup $H$. avenae'ye karşı bu genler 1slah programlarında rutin olarak kullanılmaktadır (Ogbonnaya ve ark., 2001, de Majnik ve ark.,2003). Dünya genelinde biyoteknolojik bitkilerin ekiliş alanları giderek artış göstermektedir. 1996 y1lında toplamda 2.8 milyon ha'lık bir alanda ekimi yapılırken 2017 yılı itibari ile 191.7 milyon ha'a ulaşmıştır (James, 2014, ISAAA, 2021). İleriki yıllarda ekim alanları daha da artış gösterecektir. Transgenik özelliğe sahip bitkilerin tüketimi konusunda gıda güvenliği açısından bir sorun yokmuş gibi düşünülse de tüketicilerin bu konu hakkındaki olumsuz düşünceleri aşılamamaktadır. Toplumda oluşan biyoteknolojik çalışmalar sonucu üretilen ürünlerin kullanımı konusundaki yanlış algıların ortadan kalkması için insan, çevre ve hedef alınmayan organizmalara karşı etkinliği ile ilgili çalışmalar daha detaylı bir şekilde yapılmalı ve elde edilen sonuçlar hem üreticiler hem de tüketiciler ile paylaşılmalı böylece bu konudaki bilinçliliğin arttırılması sağlanmalıdır. Hızla ilerleyen teknoloji sayesinde bitki-nematod ilişkilerinin daha iyi anlaşılması sonucu nematod mücadelesi ile ilgili çalışmalarında buna paralel olarak her geçen gün artarak, yüksek kalitede ve verimde ürün üretmeyi hedefleyen tarımsal pazarın ihtiyacı doğrultusunda gelişeceği ve biyoteknolojik çalışmaların, entegre savaşım veya iyi tarım uygulamaları içerisinde daha fazla yer alacağı düşünülmektedir

\section{Kaynakça}

Agrios, G.N. (2005). Plant pathology, Elsevier Academic Press pp. 825-874, USA.

Atkinson, H.J., Urwin, P.E. \& Hussey, R.S. (2009). 15 Plant Biotechnology and Control. Root-knot nematodes, pp.338362.

Baker, J.E., Fabrick, J.A., Kanost, M.R., Reeck, G.R., Kramer, K.J., \& Behnke, C.A. (1997). Proteinase inhibitors and resistance of transgenic plants to insects. In Advances in insectcontrol: the role of transgenic plants. CRC Press 1997.

Bakker, E., Achenbach, U., Bakker, J., Van Vliet, J., Peleman, J., Segers, B., der Heijden, S., Van der Linde, P., Graveland, R., Hutten, R., Van Eck, H., Coppoolse, E., Van der Vossen, E., Bakker, J., \& Goverse, A. (2004). A high resolution map of the H1 locus harbouring resistance to the potato cyst nematode Globodera rostochiensis. Theoretical and Applied Genetics, 109,146-152.

Boag, B., \& Yeates, G.W. (1998). Soil nematode biodiversity in terrestrial ecosystems. Biodiversity and Conservation, 7(5), 617-630.

Burrows, P.R., \& De Waele, D.(1997). Engineering resistance against plant parasitic nematode susing anti-nematodegenes. In: Fenoll C, Grundler FMW, Ohl SA, eds. Cellular and molecular aspects of plant-nematode interactions. 
Dordrecht, the Netherlands: KluwerAcademicPress, pp. 217- 236.

Cai, D., Thurau, T., Tian, Y., Lange, T., Yeh, K.W., \& Jung, C. (2003). Sporamin mediated resistance to beet cyst nematodes (Heterodera schachtiiSchm.) is dependent on trypsin inhibitory activity in sugar beet (Beta vulgaris L.) hairy roots. Plant Molecular Biology, 51(6), 839-849.

Cowgill, S.E., Wright, C. \& Atkinson, H.J. (2002)a.Transgenic potatoes with enhanced levels of nematode resistance do not have altered susceptibility to nontarget aphids. MolecularEcolology11, 821-827.

Cowgill, S.E., Bardgett, R.D., Kiezebrink, D.T. \& Atkinson, H.J. (2002)b. The effect of transgenic nematode resistance on non target organisms in the potato rhizosphere. JournalAppliedEcology 39, 915-923.

Cowgill, S.E., \&Atkinson, H.J. (2003). A sequential approach to risk assessment of transgenic plants expressing protease inhibitors: effects on non target herbivorous insects. TransgenicResearch 12, 439-449.

Cowgill, S.E., Danks, C., \& Atkinson, H.J. (2004). Multitrophic interactions involving genetically modified potatoes, nontarget aphids, natural enemies and hyperparasitoids. Molecularecology, 13(3), 639-647.

Dağeri, A., Güz, N., \& Gürkan, M.O.(2012). A New Approach to Insect Pest Management: RNA interference. Turkish Bulletin of Entomology, 2(3), 223-230.

deMajnik, J., Ogbonnaya, F.C., Moullet, O., \& Lagudah, E.S.(2003). The Cre1 and Cre3 nematode resistance genes are located at homeologous loci in the wheat genome. Molecular Plant-Microbe Interactions, 16(12), 1129-1134.

Dinh, P.T.Y., Brown, C.R., \& Elling, A.A. (2014). RNA interference of effector gene Mc16D10L confers resistance against Meloidogyne chitwoodi in Arabidopsis and potato. Phytopathology, 104, 1098-1106.

Fairbairn, D.J., Cavallaro, A.S., Bernard, M., Mahalinga-Iyer, J., Graham, M.W., \&Botella, J.R. (2007). Host-delivered RNAi: an effective strategy to silence genes in plant parasitic nematodes. Planta 226, 1525-1533.

Fire, A., Xu, S., Montgomery, M.K., Kostas, S.A., Driver, S.E., \& Mello, C.C. (1998). Potent and specific genetic interference by double-stranded RNA in Caenorhabditis elegans. Nature 391, 806-811.

Fleming, C.C., McKinney, S., McMaster, S., Johnston, M.J.G., Donnelly, P., Kimber, M.J., \& Maule, A.G. (2007). Getting to the root of neuronal signalling in plant-parasiticnematode susing RNA interference. Nematology9, 301-315.

Fosu-Nyarko, J., \&Jones, M.G., (2015). Chapter FourteenApplication of biotechnology for nematode control in crop plants. Advances in Botanical Research, 73, 339-376.

Freckman, D.W., \& Baldwin, J.G., (1990). Nematoda. Soil biology guide. Wiley, New York, pp. 155-200.

Fuller, V.L., Lilley, C.J., Atkinson, H.J., \& Urwin, P.E. (2007). Differential gene expression in Arabidopsis following infection by plant-parasitic nematodes Meloidogyne incognita and Heterodera schachtii. Molecular Plant Pathology. 8, 595-609.

Fuller, V.L., Lilley, C.J., \& Urwin, P.E. (2008). Nematode resistance. New Phytologist, 180, 27-44.

Gheysen, G., \& Vanholme, B. (2007). RNAi from plants to nematodes. Trends in Biotechnology, 25, 89-92.

Hamamouch, N., Li, C., Hewezi, T., Baum, T.J., Mitchum, M.G., Hussey, R.S., Vodkin, L.O., \& Davis, E.L., (2012). The interaction of the novel $30 \mathrm{C} 02$ cyst nematode effector protein with a plant beta-1,3 endo glucanase may suppress host defence to promote parasitism. Journal of Experimental Botany, 63, 3683-3695.

Harris, R.F. (1981). Effect of water potential on microbial growth and activity. Water Potential Relations in Soil Microbiology, 23-95.

Hepher, A., \& Atkinson, H.J. (1992). Nematode control with protease inhibitors. European Patent Publication.Number 0,502,730 A, 1.

Hilder, V.A., Gatehouse, A.M., Sheerman, S.E., Barker, R.F., \& Boulter, D. (1987). A novel mechanism of insect resistance engineered into tobacco. Nature, 330(6144), 160-163.

Hohn, T. (2007). Plant virüs transmission from the insect point of view. Proceedings of the National Academy of Sciences of the United States of America, 13, 104(46),17905-17906.

Huang, G.Z., Allen, R., Davis, E.L., Baum, T.J., \& Hussey, R.S. (2006)a. Engineering broad root-kno tresistance in transgenic plants by RNAi silencing of a conserved and essential root-knot nematode parasitism gene. Proceedings of the National Academy of Sciences, USA 103,1430214306.

Huang, G., Dong, R., Allen, R., Davis, E.L., Baum, T.J., \& Hussey, R.S., (2006)b. A root-knot nematode secretory peptide functions as a ligand for a plant transcription factor. Molecular Plant-Microbe Interactions 19, 463-470.

Ibrahim, H. M., Hosseini, P., Alkharouf, N. W., Hussein, E. H., Abd El Kader, Y., Aly, M. A., \& Matthews, B. F. (2011). Analysis of gene expression in soybean (Glycinemax) roots in response to the root knot nematode Meloidogyne incognita using micro arrays and KEGG pathways. BMC genomics, 12(1), 1-16.

ISAAA, 2021. International Service for theAcquisition of AgriBiotech Applications (ISAAA) https://www.isaaa.org/resources/publications/biotech_bookl ets/beyondpromises/download/default.asp [Erişim Tarihi: 04.04.2021]

James, C., (2014). Global Status of Commercialized Biotech. ISAAA No. Brief. 49. ISAAA: Ithaca, NY. 2014.

Jammes, F., Lecomte, P., de Almeida Engler, J., Bitton, F., Martin-Magninette, M.L., Renou, J.P., Favery, B., \&Abad, P. (2005). Genome-wide expression profiling of the host response to root-knot nematode infection in Arabidopsis. PlantJournal 44, 447-458.

Jorgensen, R.A., Cluster, P.D., English, J., Que, Q., \& Napoli, C.A. (1996). Chalcone synthase cosuppression phenotypes in petunia flowers: comparison of sense vs. antisense constructs and single-copy vs. complex T-DNA sequences. Plant Molecular Biology 31, 957-973.

Keen, N. (1999). Mechanisms of pestresistance in plants, pp. 33 36. Proceeding of A Workshop on Ecological Effects of Pest Resistance Genes in Managed Ecosystems (31 January-3 February, 1999, Bethesda, Maryland, USA), 131.

Kepenekci, İ. (2012). Nematoloji (Bitki Paraziti ve Entomopatojen Nematodlar) [Genel 4 Nematoloji (Cilt-I) ISBN 978-605-4672-11-0, TaksonomikNematoloji (Cilt-II) 5 ISBN 978- 605-4672-12-7] Eğitim, Yayım ve Yayımlar Dairesi Başkanlığı, 6 Tarım Bilim Serisi Yayın No:3 (2012/3), LIV+1155.

Klink, V. P., Kim, K. H., Martins, V., MacDonald, M. H., Beard, H. S., Alkharouf, N. W., ... \& Matthews, B. F. (2009). A correlation between host-mediated expression of parasite genes as tandem inverted repeats and abrogation of 
development of female Heterodera glycines cyst formation during infection of Glycine max. Planta, 230(1), 53-71.

Li, X.Q., Wei, J.Z., Tan, A., \& Aroian, R.V. (2007). Resistance to root-knot nematode in tomato roots expressing a nematicidal Bacillus thuringiensis crystal protein. Plant Biotechnology Journal 5, 455-464.

Lilley, C.J., Bakhetia, M., Charlton, W.L., \& Urwin, P.E., (2007). Recent progress in the development of RNA interference for plant parasitic nematodes. Molecular Plant Pathology, 8, 701-711.

Lin, B., Zhuo, K., Wu, P., Cui, R., Zhang, L.H., \&Liao, J., (2013). A novel effector protein, MJ-NULG1a, targeted to giant cell nuclei plays a role in Meloidogyne javanica parasitism. Molecular Plant-Microbe Interactions, 26, 5566.

Lopes-Caitar, V.S., Pinheiro, J.B. \& Marcelino-Guimaraes, F.C. (2019). Nematodes in horticulture: An overview. Journal of Horticultural Science and Crop Research, 1(1), 106.

Maggenti, A.R., (1991). Nemata: higher classification. Manual of Agricultural Nematology, Marcel Decker, New York, 147187.

Marban-Mendoza, N., Jeyaprakash, A., Jansson, H.B., Damon, R.A., \&Zuckerman, B.M. (1987). Control of root-knot nematodes on tomato by lectins. Journal of Nematology 19, 331-335.

Marroquin, L.D., Elyassnia, D., Griffitts, J.S., Feitelson, J.S., \& Aroian, R.V. (2000). Bacillus thuringiensis (Bt) toxin susceptibility and isolation of resistance mutants in the nematode Caenorhabditis elegans. Genetics, 155(4), 16931699.

Nicol, J.M., Turner, S.J., Coyne, D.L., Den Nijs, L., Hockland, S., \& Maafi, Z.T. (2011). Current nematode threats to World agriculture. In Genomics and molecular genetics of plantnematode interactions Springer Netherlands 21-43.

Ogbonnaya, F.C., Subrahmanyam, N.C., Moullet, O., De Majnik, J., Eagles, H.A., Brown, J.S., Eastwood, R.F., Kollmorgen, J., Appels, R., \& Lagudah, E.S., (2001). Diagnostic DNA markers for cereal cyst nematode resistance in bread wheat. Australian Journal of Agricultural Research, 52(12), 1367-1374.

Oka, Y., Chet, I., \& Spiegel, Y. (1997). An immunoreactive protein to wheat-germ agglutinin antibody is induced in oat roots following invasion of the cereal cyst nematode Heterodera avenae, and by jasmonate. Molecular PlantMicrobe Interactions 10: 961-969.

Oka, Y. (2020). From Old-Generation to Next-Generation Nematicides. Agronomy, 10(9), 1387.

Öktem, H.A. (2001). Böceklere Dayanıklı Transgenik Bitkilerin Geliştirilmesi; Bitki BiyoteknolojisiEdt.; Sebahattin Özcan, Ekrem Gürel, Mehmet Babaoğlu, Türkiye.

Özcan, S. (2001). Bitki Biyoteknolojisi Edt.; Sebahattin Özcan, Ekrem Gürel, Mehmet Babaoğlu, Türkiye.

Patel, N., Hamamouch, N., Li, C., Hussey, R., Mitchum, M., Baum, T., Wang, X., \& Davis, E.L. (2008). Similarity and functional analyses of expressed parasitism genes in Heterodera schachtii and Heterodera glycines. Journal of Nematology, 40, 299-310.

Pekcan, G., Köksal, E., Küçükerdönmez, Ö., \& Özel, H., (2006). Household food waste in Turkey. Statistics Division, Working Papersseries NESS/ESSA/006e. Rome, FAO.

Perry, R.N., \& Moens, M., (2006). Ectoparasitic Nematodes, Plant Nematology CABI, Belgium 266-271.
Peumans, W.J., \&Van Damme, E.J.M. (1995). Lectins as plant defense proteins. Plant Physiology, 109: 347-352.

Ryan, C.A. (1990). Protease inhibitors in plants: genes for improving defenses against insect sand pathogens. Annual review of phytopathology, 28(1), 425-449.

Sindhu, A.S., Maier, T.R., Mitchum, M.G., Hussey, R.S., Davis, E.L., \& Baum, T.J. (2009). Effective and specific in planta RNAi in cyst nematodes: expression interference of four parasitism genes reduces parasitic success. Journal of Experimental Botany, 60, 315-324.

Steeves, R.M., Todd, T.C., Essig, J.S., \& Trick, H.N. (2006). Transgenic soybean sexpressings iRNAs specific to a major sperm protein gene suppress. Heterodera glycines reproduction. Functional Plant Biology 33, 991-999.

Thorne, G. 1961. Principles of Nematology. Principles of Nematology 1961.

Thurau, T., Ye, W., \& Cai, D. (2010). Insect and nematode resistance. In GeneticModification of Plants Springer Berlin Heidelberg. 177-197.

Toros, S., Maden, S., \& Sözeri, S. (1991). Tarımsal Savaşım Yöntem ve İlaçları. Ankara Üniversitesi Ziraat Fakültesi Yay, 1222.

Urwin, P.E., Lilley, C.J., McPherson, M.J., Atkinson, H.J. (1997). Resistance to both cyst- and root-knot nematodes conferred by transgenic Arabidopsis expressing a modified plant cystatin. Plant Journal12, 455-461.

Urwin, P.E., McPherson, M.J., \& Atkinson, H.J., (1998). Enhanced transgenic plant resistance to nematodes by dual proteinase inhibitör constructs. Planta, 204, 472-479.

Urwin, P.E., Levesley, A., McPherson, M.J., \&Atkinson, H.J., (2000). Transgenic resistance to the nematode Rotylenchulus reniformis conferred by Arabidopsis thaliana plants expressing proteinase inhibitors. Molecular Breeding, 6, 257- 264.

Vai, P., Worland, B., Clarke, M.C., Richard, G., Beavis, M., Liu, H., Kohli, A., Leech, M., Snape, J., Christou, P., \&Atkinson, H., (1998). Expression of an engineered cysteine proteinase inhibitor $(\mathrm{OC}-\mathrm{I} \Delta \mathrm{D} 86)$ for nematode resistance in transgenic rice plants. TheoreticalandApplied Genetics, 96, 266271.

Valentine, T.A., Randall, E., Wypijewski, K., Chapman, S., Jones, J., \& Oparka, K.J. (2007). Delivery of macro molecules to plant parasitic nematodes using a tobacco rattle virüs vector. Plant Biotechnology Journal 5, 827-834.

Vishnudasan, D., Tripathi, M.N., Rao, U., Khurana, P. (2005). Assessment of nematode resistance in wheat transgenic plants expressing potato proteinase inhibitor (PIN2) gene. Transgenic Research 14, 665-675.

Waterhouse, P.M., Graham, M.W., \& Wang, M.B., (1998). Virus resistance and gene silencing in plants can be induced by simultaneous expression of sense and antisense RNA. Proceedings of the National Academy of Sciences, USA 95, 13959-13964.

Wei, J.Z., Hale, K., Carta, L., Platzer, E., Wong, C., Fang, S.C., \&Aroian, R.V. (2003). Bacillus thuringiensis crystal proteins that target nematodes. Proceedings of the National Academy of Sciences, USA 100, 2760-2765.

Yadav, B.C., Veluthambi, K. \& Subramaniam, K. (2006). Hostgenerated double stranded RNA induces RNAi in plantparasitic nematodes and protects the host from infection. Molecular and Biochemical Parasitology 148, 219- 222. 